\title{
“As long as you need me I'm yours.” Caregiving for a pediatric cancer survivor
}

\author{
Monica Lynn Molinaro*1, Paula Christine Fletcher ${ }^{2}$ \\ ${ }^{1}$ Health and Rehabilitation Sciences, The University of Western Ontario, London, Canada \\ ${ }^{2}$ Department of Kinesiology and Physical Education, Wilfrid Laurier University, Waterloo, Canada
}

Received: August 3, 2016

DOI: $10.5430 / \mathrm{cns} . v 4 \mathrm{n} 4 \mathrm{p} 23$
Accepted: August 21, $2016 \quad$ Online Published: September 9, 2016

URL: http://dx.doi.org/10.5430/cns.v4n4p23

\begin{abstract}
A pediatric cancer diagnosis is devastating - to children, as well as their families. Children experience a variety of negative effects, whether physical, cognitive, and/or emotional, and often face continued or newly developed effects 1 past remission termed late effects. However, it is imperative to note that support persons, or caregivers of survivors of pediatric cancer, are also affected by their caregiver roles as they help their survivors cope with their late effects. This study aimed to understand how caring for pediatric cancer survivors influences facets of caregivers lives. Nine primary support persons of pediatric cancer survivors (as chosen by the survivors they care for) participated in one-on-one, semi-structured interviews, in which they discussed their roles in caring for a pediatric cancer survivor, and how being a support person has affected their lives. A total of four themes emerged from the research, but for the purposes of this paper only the theme "As long as you need me I'm yours" will be discussed. From this theme, two subthemes emerged: (1) "Do their effects affect me?" and (2) "You realize what's important and it sticks with you." Support persons experienced negative emotional and cognitive effects, such as worrying or feelings of anxiety for their survivors, but also admitted to finding silver linings in their experiences. As well, caregivers expressed that they have developed stronger relationships with their survivors and family, in addition to developing newly optimistic outlooks on life. This work provides valuable information for policy makers and health care professionals to ensure that adequate supports and resources are available to caregivers for the multifaceted needs they may have in supporting pediatric cancer survivors.
\end{abstract}

Key Words: Pediatric cancer, Caregiver, Caregiving, Survivors

\section{INTRODUCTION}

During the pediatric cancer journey children with cancer are not the only individuals experiencing a multitude of effects. ${ }^{[1-7]}$ While much work has been invested in studying the effects of cancer on the child, it is also important to understand the effects of a pediatric cancer diagnosis on individuals close to the children - particularly immediate family members, such as parents and siblings. Previous research has described both costs and benefits of a pediatric cancer diagnosis, although the majority of research is negative in nature.
For example, during treatment, parents have felt high levels of stress and fatigue, and sometimes had relationship issues with their spouses, as previous studies demonstrated. ${ }^{[1-3,5,7,8]}$

In the years following cancer treatment, caregivers may be faced with the continued effects resulting from caring for pediatric cancer survivors. For example, research conducted by Patterson et al. ${ }^{[7]}$ discovered that many parents experienced stress regarding the effects that cancer treatment would have on the future lives and health of their children. Parents expressed the continued worry concerning the fertility of their

\footnotetext{
* Correspondence: Monica Lynn Molinaro, MSc.; Email: mmolina3@uwo.ca; Address: Health and Rehabilitation Sciences, The University of Western Ontario, London, Ontario, N6G 1H1, Canada.
} 
children after their experiences with cancer and even went as far as to look into fertility treatments, including sperm banking. Further, many parents articulated that they were fearful of relapse, and that they were more vigilant in observing the needs of their children with cancer when they were sick - even after the cancer treatment had ended. Conversely, Clarke et al. ${ }^{[2]}$ interviewed 25 mothers (aged 31 to 46 ) of children who had cancer (aged 3 to 18), about their roles in being at home and providing health care to their children. Many of the mothers discussed that going through pediatric cancer made them have a more positive outlook on life because they became more appreciative of the health of their family and everything that they had. While literature exists regarding caring for pediatric cancer survivors, much of the literature focuses on one demographic, such as mothers, or on specific aspects of caregiving, such as providing health care. It is imperative to understand that caregiving or being a support person spans beyond the scope of the survivors' family, and that the effects of caregiving for a pediatric cancer survivor are often multifaceted and varied for each support person. The purpose of this study was to gain a better understanding of the effects that caring for pediatric cancer survivors had on caregivers.

\section{MethodS}

\subsection{Participants}

After all tools and procedures were approved by a university ethics board, participants were recruited through word of mouth and advertisements to societies and support groups for pediatric cancer in Ontario, Canada. As the primary support persons were recruited based on their relationships with their pediatric cancer survivors currently, support persons did not necessarily have to be present during the survivors' diagnosis and treatment, as they were being recruited to elaborate on any late effects the survivors were currently experiencing, and not the effects they experienced when undergoing treatment.

\subsection{Background questionnaires}

A background questionnaire was administered to participants, which consisted of items pertaining to: (1) demographic information such as age, education, employment, and relationship status; (2) their knowledge of the diagnosed individuals' past cancer experiences; and (3) their role as primary support persons. The information from these background questionnaires was used to create context for the interviews.

\subsection{Interviews}

Each participant took part in a one-on-one, semi-structured interview conducted by the principal researcher. The interviews were arranged at a time and place convenient to the interviewee and were conducted either in person or via telephone. The interviews lasted an average of 56 minutes. Each interview consisted of 13 open-ended questions consisting of background and demographic information, information regarding the pediatric cancer survivors and their experiences with cancer, current life as support persons for the diagnosed individuals, and any late effects that the survivors were currently experiencing. Subsequently, each interview was transcribed verbatim so that data analysis could begin and saturation of information could be monitored collected throughout the recruitment process. Each participant was given an alphanumerical code (e.g. S1, SP1, etc.) in place of their name, and all identifiers were removed from these transcripts before data analysis. After data analysis had been completed, each participant was given a pseudonym to accompany their quotes without revealing their identities.

\subsection{Data analysis}

To fulfill the purpose and answer the research questions of this study, the most appropriate methodology to use was qualitative in nature, as these methods allowed for a holistic understanding of a particular experience or phenomenon. Specifically, the theoretical orientation chosen for this research was phenomenology. In phenomenology, "one must undertake in depth interviews with people who have directly experienced the phenomenon of interest; that is, they have 'lived experience' as opposed to 'secondhand experience'" [9] (p. 104). Using such methodologies allowed for the true "voices" of the participants to be conveyed in order for readers to fully understand the essence of their experiences. This theoretical approach was most fitting because the purpose of the study was to explore the lived experiences of pediatric cancer survivors and their primary support persons, and this particular paper focuses on the effect of caring for a pediatric cancer survivor on their primary support persons.

In order to allow the "voices" of the participants to emerge by using phenomenology, a step-by-step analysis of the data, generally based around the framework of Moustakas ${ }^{[10]}$ was completed. The experiences of the participants were divided into past and present (i.e. their experiences when the diagnosed individual was undergoing treatment and their current experiences in caring for the individual). For the support persons that were not present during the survivors' cancer experiences, their transcripts were only coded for the current time period. From this initial coding process, transcripts were then re-examined for how support persons believed potential aspects of their lives had been affected (e.g. physical, cognitive, social, etc.). These effects were also coded by how the individuals were affected (i.e. positively, negatively, or not at all). This allowed for the emergence of subthemes 
regarding how caring for survivors affects support persons. to life the way in which the facets of their lives had been Subsequent to the discovery of the subthemes, transcripts affected, and these quotes were used verbatim. were read again to highlight particular quotes that brought

Table 1. Demographic information for pediatric cancer survivors

\begin{tabular}{|c|c|c|c|c|c|}
\hline Participant & Jon & Sarah & James & Brenna & Adam \\
\hline Diagnosis & $\begin{array}{l}\text { Benign Thalamic } \\
\text { Astrocytoma }\end{array}$ & $\begin{array}{l}\text { Acute Lymphoblastic } \\
\text { Leukemia }\end{array}$ & $\begin{array}{l}\text { Acute Lymphoblastic } \\
\text { Leukemia }\end{array}$ & Acute Myeloid Leukemia & Hodgkin’s Lymphoma \\
\hline Age at Diagnosis & 8 & $3 \frac{1}{1} / 2$ & 11 & 14 & 13 \\
\hline Late Effects & $\begin{array}{l}\text { Right homonymous } \\
\text { hemianopia } \\
\text { Ataxia } \\
\text { Visual scanning delay } \\
\text { Visual/Verbal short term } \\
\text { memory }\end{array}$ & $\begin{array}{l}\text { Lesser heart fibres } \\
\text { Anxiety }\end{array}$ & $\begin{array}{l}\text { Stunted growth } \\
\text { Sexual health issues }\end{array}$ & $\begin{array}{l}\text { Survivor's guilt } \\
\text { Depression } \\
\text { Right leg partial amputation } \\
\text { Memory issues } \\
\text { (chemo-brain) }\end{array}$ & $\begin{array}{l}\text { Decreased lung capacity } \\
\text { Weakened tooth enamel }\end{array}$ \\
\hline Participant & Casey & Brielle & Allie & Spencer & Julia \\
\hline Age at Diagnosis & 2 & $3 \frac{1}{1 / 2}$ & 19 & 15 & 17 \\
\hline Treatment & Chemotherapy & $\begin{array}{l}\text { Chemotherapy } \\
\text { Radiation therapy }\end{array}$ & $\begin{array}{l}\text { Chemotherapy } \\
\text { Radiation therapy } \\
\text { Stem cell transplant }\end{array}$ & Chemotherapy & Chemotherapy \\
\hline Current Age & 28 & 24 & 22 & 22 & 24 \\
\hline Late Effects & $\begin{array}{l}\text { Needle-phobia } \\
\text { Claustrophobia }\end{array}$ & $\begin{array}{l}\text { Poor eyesight } \\
\text { Tooth formation issues }\end{array}$ & $\begin{array}{l}\text { Joint pain } \\
\text { Gall bladder removal } \\
\text { Muscle spasms and cramps } \\
\text { Migraines } \\
\text { Fatigue } \\
\text { Memory issues (chemo-brain) } \\
\text { Menopause }\end{array}$ & $\begin{array}{l}\text { Nerve damage in legs } \\
\text { Sleep apnea } \\
\text { Heightened learning disability } \\
\text { Anxiety } \\
\text { Depression }\end{array}$ & $\begin{array}{l}\text { Avascular necrosis in } \\
\text { bones - resulted in two } \\
\text { hip replacements } \\
\text { Bone in foot is dead }\end{array}$ \\
\hline
\end{tabular}

Table 2. Demographic information for support persons

\begin{tabular}{|c|c|c|c|c|c|c|c|c|c|}
\hline Support Person & Mary & Kristen & Susan & Sheila & Louise & Kyle & Nadia & Chloe & Elizabeth \\
\hline Support Person to: & Jon & Sarah & James & Brenna & Adam & Casey & Allie & Spencer & Julia \\
\hline $\begin{array}{l}\text { Relationship with } \\
\text { Participant }\end{array}$ & Mother & Mother & Mother & Mother & Mother & Boyfriend & Mother & Fiancée & Grandmother \\
\hline Current Age & 54 & 50 & 58 & 55 & 48 & 31 & 62 & 23 & 73 \\
\hline $\begin{array}{l}\text { Present during } \\
\text { cancer experience? }\end{array}$ & Yes & Yes & Yes & Yes & Yes & No & Yes & No & Yes \\
\hline $\begin{array}{l}\text { Support provided } \\
\text { to participant at } \\
\text { present time }\end{array}$ & $\begin{array}{l}\text { Emotional } \\
\text { Financial }\end{array}$ & $\begin{array}{l}\text { Emotional } \\
\text { Financial }\end{array}$ & $\begin{array}{l}\text { Emotional } \\
\text { Financial } \\
\text { Cognitive } \\
\text { Physical } \\
\text { Psychological } \\
\text { Social }\end{array}$ & $\begin{array}{l}\text { Emotional } \\
\text { Financial } \\
\text { Cognitive } \\
\text { Physical } \\
\text { Psychological } \\
\text { Social }\end{array}$ & Financial & $\begin{array}{l}\text { Emotional } \\
\text { Physical } \\
\text { Social }\end{array}$ & $\begin{array}{l}\text { Emotional } \\
\text { Financial } \\
\text { Cognitive } \\
\text { Physical } \\
\text { Psychological } \\
\text { Social }\end{array}$ & $\begin{array}{l}\text { Emotional } \\
\text { Financial } \\
\text { Cognitive } \\
\text { Physical } \\
\text { Psychological } \\
\text { Social }\end{array}$ & $\begin{array}{l}\text { Emotional } \\
\text { Financial } \\
\text { Cognitive } \\
\text { Physical } \\
\text { Psychological } \\
\text { Social }\end{array}$ \\
\hline
\end{tabular}

\section{Results}

The support persons included six mothers, one boyfriend, one fiancée, and one grandmother, ranging in age from 23 to 73. Of the nine support persons in the study, seven of them were also the primary support persons for the survivors while undergoing their pediatric cancer experiences (the six mothers and one grandmother). More information regarding the caregivers and survivors can be seen in Tables 1 and 2 .

The quote "As long as you need me I'm yours" was shared

Published by Sciedu Press by Elizabeth, grandmother to Julia. At the beginning of her cancer treatment, Elizabeth explained that she often said this phrase to Julia to let her know that, regardless of the circumstances, she would be there to care for Julia whenever and in whatever ways she would need it. The same could be said with the other support persons recruited for this study, who all provided care for their survivors whenever they were in need. For the majority of survivors, support persons provided psychological and financial support, however they stated that 
the survivors were predominantly self-sufficient. All support persons indicated that their lives had changed as a result of caring for the survivors, regardless of whether or not they were present for the cancer experiences. The effects were not to the extent, or as negative as the effects described by survivors; however, the experiences of the support persons were still integral in describing the lived experiences of life past remission for individuals who had pediatric cancer. Within this theme, two subthemes emerged concerning the caregivers: (1) "Do their effects affect me?" and (2) "You realize what's important and it sticks with you." Each of these will be discussed in turn.

\section{1 "Do their effects affect me?"}

Caregivers conveyed that they currently experienced no physical effects as a result of being support persons for pediatric cancer survivors, although some of the mothers present for their children's cancer journeys had experienced physical effects during the specific time period of cancer treatments. Any physical ailments or difficulties experienced by support persons when interviewed were attributed to factors completely separate from their caregiving. Additionally, none of the support persons reported any cognitive effects in relation to their caregiving responsibilities. Conversely, some support persons claimed that they experienced compromised mental or emotional effects as a direct result of their cancer experiences with their survivors. The following quotes illustrated the constant worry and anxiety experienced by support people.

“... he's easy to, make friendships, I think. And in some ways he can be naïve. I sometimes am concerned because I think he trusts people [pause] too much. And not everyone has good intentions, and most people do! But you just have to be careful. ... I don't always know if he, can, read those signals?" - Mary (Mother of Jon)

“... I mean my life has definitely become more stressful, cause I worry about him and I worry every time we go to a doctor's appointment to see if it's come back and, but like, [sighs] I would say my way of handling - it hasn't really changed." Chloe (Fiancée of Spencer)

“Mentally... with the stress factor, and, cause you're always going always worried. Even now, you know when his, he has to go for his check-up I don't go with him. But I want him to text me and let me know [laughs] that everything's okay." Louise (Mother of Adam)

Kristen believed that in being with Sarah during her cancer experience, she managed stress differently and became emotionally distant in order to protect herself from being hurt:
“... I can probably tell you that I handle things differently. In terms of emotion. I maybe, set, set things a little further away from me and maybe don't, don't let myself in, as, as often or as deeply as I once did." - Kristen (Mother of Sarah)

Sheila developed severe anxiety and post-traumatic stress disorder as a result of Brenna's cancer experience, conditions that she still lives with today:

"I've suffered post-traumatic stress disorder. [pause, lowers voice] Yeah, yeah it's been bad. I've been going to a psychiatrist ever since....I still get flashbacks....it still causes me anxiety....my psychiatrist is in [city] and when I drive that way past the hospital I still get anxiety. And I'm still on medication.” - Sheila (Mother of Brenna)

Conversely, Nadia reported that her experiences aided her in coping with stress:

“... you know you can kind of laugh at some of the things that, you're about to worry about. . little minor details about you know.... have to get this I have to get that and you think 'well why am I stressing about that?'” - Nadia (Mother of Allie)

It was evident that support persons very deeply cared for the survivors, and as such, experienced psychological effects in caring for them, effects that persisted past the treatment phases and to the present time.

Like survivors, more than half of the support persons also felt that aspects of their lives had changed as a result of caring for their survivors. Other support persons stated that aspects of their lives were simply reinforced, rather than changed. Regardless of whether they were present for the cancer experiences, those who admitted experiencing changes acknowledged that aspects of their personalities had changed, primarily for the better. Susan, having been diagnosed with breast cancer after James's cancer experience, knew that going through the experience with him helped prepare her for her treatment:

"Definitely I think...you're hyper vigilant, over little things....I, guess I saw a more personal side of medicine, that, um, yeah I respected that so. I expected that when I started my treatments, that nothing would be held back. That I would be, um, responsible for my care as much as the oncologist. So yeah it did affect my personality." - Susan (Mother of James)

Chloe became more accepting and tolerant of others, as she knew that anyone could have faced a hard battle unbeknownst to her:

“... I would say I'm more aware of things now like... because, if you look at Spencer from the outside like he looks happy 
he looks normal he looks, like you would never know he had cancer before....I've just learned that there's a lot under the surface to people that you don't, necessarily, see, or know of, but it can be there." - Chloe (Fiancée of Spencer)

Kyle became more protective of Casey:

“... I'm more aware like I have a lot of friends who smoke cigarettes, um so I'm more aware of that kind of thing when we go out. [I] try to like keep her away from that secondhand smoke a lot." - Kyle (Boyfriend of Casey)

Louise and Sheila learned to advocate for their children. Although addressing the past, both Louise and Sheila believed this allowed them to continue advocating for their children and other family members going through medical treatments to this day:

"You have to learn to be patient [laughs] or more patient. You have to learn to advocate. If you don't understand something, or or, Adam didn't understand something, you had to push for an answer....So y-you, learn to advocate more so that was a, a good thing on my part." - Louise (Mother of Adam)

“...I was very - well, hyper vigilant probably but, I was so careful. I went to every test with her and checked everything and, yeah... you really have to advocate for your children because, and they even said that to me the kids that do well are the ones that have parents who really advocate for them. And it's the poor little ones in there that don't have anybody watching for them that don't do well." - Sheila (Mother of Brenna)

The support persons were in consensus that overall, they experienced changes as a result of providing care to pediatric cancer survivors. For some, the changes were mental in nature, while others shared that their personalities had changed.

\section{2 'You realize what's important and it sticks with you."}

Most support persons believed that their perspectives on life, as well as aspects of their lives that they valued, had changed because of their roles as support persons. More specifically, support persons discussed that they were more appreciative of the lives they had. Some of the support persons discussed how they valued their family and friends more than ever before as a result of their roles as caregivers for a pediatric cancer survivors.

“... you have to make time for yourself and your friends and your family and, all this, running around and doing things for nothing is just, crazy. Like getting caught up in all that craziness of the world it's just, you have to take time." - Sheila (Mother of Brenna)

Published by Sciedu Press
“... I think sort of spending time with each other, being a part of each other's, you know day to day life. I mean we value all those things. We did in the past, but uh, I think it's a lot stronger now." - Nadia (Mother of Allie)

“... you just, realize... what's important. And you, go through those things, and you have, you know, you hug your kids every day, and... maybe you live in the moment a little more, uh and you understand... that emotion, and family, and people, are the most important. . . everything else can come and go." - Kristen (Mother of Sarah)

After Jon's surgery, and still to this day, it was all about the little things that happen in life. Mary commented:

"I remember driving up a country road and smelling the flowers and I, we, stopped... I would have the kids in the vehicle and I would stop and go and we'd be sniffing the flowers, and it made me realize that, right now was all we have, and, it's, it's not the, how much, how big your house is or, how many cars you have or, a place in Florida or, how many trips you take a year, it's the little things, that are really important, and that's, what I've learnt." Mary (Mother of Jon)

Once again, those who acknowledged that their values changed all agreed that it was for the better. Mothers believed they developed new outlooks on life. For Louise, she had taken on a new life motto after caring for Adam:

"... my new motto is uh, I get up and face the day and I, know there are days that I need a, kick in the butt but, somewhere somebody somewhere, has it worse than I do... that became my motto when we were going through this with Adam because you're, you're looking at, the ambulances that are coming in you're looking at, the families that have lost, their children and that's like, it sucks. But, he's still here. We're fighting it. You know, somebody, somebody's having a worse day than I am. And that's the, my new philosophy." - Louise (Mother of Adam)

Some mothers embraced appreciating the smaller things, and take time for those who were important in their lives:

"... it changes, how you view the world like it makes you, appreciate what you have. It makes you [pause] it really gives you a different, perspective like you really, you make time for people. Like, one phone call can change your, your life right? Like I was driving home from work and I got that call, and your world stops. Like, it, it makes you take time for things." - Sheila (Mother of Brenna)

“... you really put things into perspective. And you really understand, uh what's important. Um, in life at that point and [clears throat] and everything else, disappears. Um, and you feel, petty, you know for some of those things that 
you used to uh, you used to think about or that u-used to bother you or worry you. So, in terms of figuring that out, that's something, that impacted my life." - Kristen (Mother of Sarah)

“... people will come in and say 'oh I've turned 65' and I'll say 'congratulations. It's really good to celebrate a birthday'. You know? It's, it's so precious. And, that's what I learned. From, Jon's diagnosis, and, through all of this and seeing, different, um, different children at [hospital] who weren't coming home, who were affected by their, brain tumours, so much, more, and um, where they, you know they, they needed so much assistance. Jon's independent, and we're blessed." - Mary (Mother of Jon)

While some support persons believed that aspects of their lives remained consistent while supporting their survivors currently, many of them felt some sort of change in some part of their lives. And, although few support persons addressed the psychological effects they experienced, most agreed that the changes they underwent and were currently experiencing were positive, and for the better.

\section{Discussion}

The support persons involved in this study, regardless of whether or not they were present during the cancer experiences, stated that their lives had been affected as a result of caring for individuals who previously had pediatric cancer. Past literature has shown that support persons (primarily parents) of individuals who had pediatric cancer mainly experienced mental or emotional effects. ${ }^{[2,11-14]}$ However, all of this literature addresses parents or caregivers that were present during the cancer experiences, and not persons that survivors may rely on in their current lives.

Some support persons admitted that although their survivors' pediatric cancer journeys were over, they still experienced worry for them. This worry was primarily in regards to the survivors' health. Support people were not necessarily concerned that they would relapse, but more so that the late effects of their cancer may become worse, that they were not as careful with their health as they should be, or that the late effects had not yet been expressed. These contentions are supported by the findings presented by Wijnber-Williams et al., ${ }^{[12]}$ who found that even after treatment, parents of pediatric cancer survivors still experienced clinical levels of stress in their day-to-day lives regarding their children, although levels were lower than the time of cancer treatment. Similarly, Van Dongen-Melman et al. ${ }^{[13]}$ reported that parents of children who had pediatric cancer have difficulty returning to a state of mental normalcy, meaning, they no longer feel completely relaxed, and question their abilities to cope should another traumatic event affect their lives.

Further, Pelcovitz et al. ${ }^{[14]}$ conveyed that mothers of pediatric cancer survivors entering the maintenance phase of treatment had a higher prevalence of post-traumatic stress disorder (PTSD) compared to mothers of "healthy" children. These findings are consistent with findings from Kilpatrick et al. ${ }^{[15]}$ who found that individuals were more likely to develop PTSD if there was a higher possibility of death of a family member due to a threatening circumstance. These results coincide with the experiences of Sheila from this study, whose daughter, Brenna, nearly died multiple times throughout the progression of her cancer treatment. It is important to note that some support persons explained that they felt they were now better equipped to handle stressful situations, as learning to cope through the cancer experience allowed them to develop better mechanisms of dealing with stress. This finding is of importance to health care professionals, who should be equipped to aid support persons of pediatric cancer patients and survivors, especially when the responses of each individual affected will differ. As such, health care professionals should be prepared for the variety of reactions and effects not only in survivors, but support persons or caregivers as well. When discussing other aspects in which their daily living had been affected in caring for their survivors, the support persons were extremely positive in their narratives. Some of the support persons stated that their personalities had changed. For Kyle and Chloe, who were not present during their significant others' cancer experiences, they stated that they were more aware and considerate towards others. In getting to know their survivors, they learned that it was difficult to truly know what individuals have gone through in their lives.

Additionally, support persons who were present at the time of cancer treatment admitted that they had become more patient, and better advocates for their family members. Overall, all support persons felt that their treatment of other people changed as a result of their experiences, and that these changes were for the better.

Further, support persons acknowledged that their values had changed. Some stated that they appreciate their families more and make a concerted effort to spend more time with their family and friends. The same results were discussed in a paper by Author, ${ }^{[4]}$ in which mothers discussed how their family and friend groups became extremely supportive during their children's cancer treatment, and that appreciation for their supports continued after the child had completed treatment. Moreover, the support persons in this study stated that they lived their lives differently now, as they discussed how they valued life more, and appreciated how precious life 
can be. We discussed similar changes with her mothers' outlooks on life. ${ }^{[4]}$ The mothers discussed how they approached situations with positivity, did not stress over the small things, and, for those whose children lived, were beyond grateful. It is important to note that ${ }^{[4]}$ the perspectives of mothers whose children had just finished treatment, or had passed away from their cancer. Although the sample ${ }^{[4]}$ was not entirely similar to the study at hand, the findings mirror the opinions of the support persons.

\section{Limitations}

There are some limitations in this study that need to be discussed. The cohort of primary support persons included individuals who were present during the cancer experiences (six mothers and one grandmother), as well as individuals who were not (one boyfriend and one fiancée). Due to this, the experiences of the caregivers were not necessarily similar. The recruitment of only support persons present during the cancer diagnosis and treatment may potentially allow for greater information regarding how families cope when a member is diagnosed with cancer, as well as currently. However, it is still important to note that the experiences of each caregiver are multifaceted and unique in nature.

Additionally, the information presented in this study reflects the point of view of only one caregiver, one of who may not have been present during the cancer experience. Information obtained from additional family members and other support persons present during cancer treatment would have allowed for a greater understanding of the effect that pediatric can- cer has on survivors and their families, including siblings, fathers, and extended family and friends.

\section{CONCLUSIONS AND IMPLICATIONS}

This study suggests that individuals caring for pediatric cancer survivors may experience stress or health effects as a result of being support persons. This research illustrates that caregivers may experience the need for help in balancing the care for their pediatric cancer survivors, as well as additional family members as time progresses. It would be favorable for policy makers to create a framework that allows for caregivers of cancer survivors to have access to additional health care resources or support networks tailored to their specific caregiving needs. Additionally, as the nature of providing care is often multifaceted in nature, ensuring that any resources or supports for caregivers are accessible at all times would also be beneficial. Moreover, the implications of this study are of importance to parents, family members, and significant others of individuals who had pediatric cancer. The development of support networks and resources available to caregivers of pediatric cancer survivors can provide immense help in understanding how to help with their late effects. Further, this research provides context for health care professionals in understanding that pediatric cancer survivors and their support networks may both experience effects from pediatric cancer.

\section{CONFLiCTS OF INTEREST Disclosure}

The Authors declare that there is no conflict of interest.

\section{REFERENCES}

[1] Clarke JN, Fletcher PC, Schneider MA. Mothers' home health care work when their children have cancer. Journal of Pediatric Oncology Nursing. 2005; 22(6): 365-373. PMid: 16216898. http: //dx.doi.org/10.1177/1043454205281834

[2] Clarke JN, Fletcher PC. When Your Child Has Cancer: A Discussion of Factors That Affect Mothers' Abilities to Cope. Journal of Psychosocial Oncology. 2003 Oct; 21(3): 81-99. http: //dx.doi.org/10.1300/J077v21n03_05

[3] Fletcher PC. My child has cancer: the costs of mothers' experiences of having a child with pediatric cancer. Issues in Comprehensive Pediatric Nursing. 2010 Jul; 33: 164-184. http://dx.doi.org/1 $0.3109 / 01460862.2010 .498698$

[4] Fletcher PC. My child has cancer: finding the silver lining in every mother's nightmare. Issues in Comprehensive Pediatric Nursing. 2011 Feb; 34: 40-55. http://dx . doi .org/10.3109/01460862. 2011.557905

[5] Fletcher PC, Schneider MA, Harry RJ. How Do I Cope? Factors Affecting Mothers' Abilities to Cope With Pediatric Cancer. Journal of Pediatric Oncology Nursing. 2010 Sept; 27(5): 285-298. http://dx.doi.org/10.1177/1043454209360839
[6] Overholser JC, Fritz GK. The Impact of Childhood Cancer on the Family. Journal of Psychosocial Oncology. 1991; 8(4): 71-85. http://dx.doi.org/10.1300/J077v08n04_05

[7] Patterson JM, Holm KE, Gurney JG. The impact of childhood cancer on the family: a qualitative analysis of strains, resources, and coping behaviours. Psycho-Oncology. 2004 Jun; 13: 390-407. http://dx.doi.org/10.1002/pon.761

[8] Phipps S. Contexts and challenges in pediatric psychosocial oncology research: Chasing moving targets and embracing "good news" outcomes. Journal of Pediatric Psychology. 2005 Jan; 30(1): 41-45. http://dx.doi.org/10.1093/jpepsy/jsi014

[9] Patton MQ. Qualitative Research and Evaluation Methods. California: Sage Publications; 2002. 104 p.

[10] Moustakas C. Phenomenological Research Methods. California: Sage Publications; 1994.

[11] Kazak AE, Barakat LP, Meeske K, et al. Posttraumatic Stress, Family Functioning, and Social Support in Survivors of Childhood Leukemia and Their Mothers and Fathers. Journal of Consulting and Clinical Psychology. 1997 Feb; 65(1): 120-129. http://dx.doi.org/10. $1037 / 0022-006 \mathrm{X} \cdot 65.1 .120$ 
[12] Wijnberg-Williams BJ, Kamps WA, Klip EC, et al. Psychological Adjustment of parents of pediatric cancer patients revisited: Five years later. Psycho-Oncology. 2006; 15: 1-8. http://dx.doi.org /10.1002/pon. 927

[13] Van Dongen-Melman JEWM, Van Zuuren FJ, Verhulst FC. Experiences of parents of childhood cancer survivors: a qualitative analysis. Patient Education and Counseling. 1998 Jul; 34: 185-200. http://dx.doi.org/10.1016/S0738-3991(98)00031-7
[14] Pelcovitz D, Goldenberg B, Kaplan S, et al. Posttraumatic Stress Disorder in Mothers of Pediatric Cancer Survivors. Psychosomatics. 1996 Mar. 37(2): 116-126. http://dx. doi.org/10.1016/S0033 $-3182(96) 71577-3$

[15] Kilpatrick DG, Saunders BE, Amick-Mcmullan A, et al. Victim and crime factors associated with the development of crime-related posttraumatic stress disorder. Behaviour Therapy. 1999; 20: 199-214 http://dx.doi.org/10.1016/S0005-7894(89)80069-3 